\title{
Effects of the Apolipoprotein E Polymorphism on Uptake and Transfer of Cell-derived Cholesterol in Plasma
}

Yadong Huang, * Arnold von Eckardstein, ${ }^{\ddagger}$ Shili Wu, * and Gerd Assmann ${ }^{\star *}$

*Institut für Arterioskleroseforschung an der Universität Münster, D-48149 Münster, Federal Republic of Germany; and

${ }^{\ddagger}$ Institut für Klinische Chemie und Laboratoriumsmedizin, Zentrallaboratorium, Westfälische Wilhelms-Universität Münster,

Federal Republic of Germany

\begin{abstract}
The reverse cholesterol transport is initiated by the uptake of cholesterol into minor subfractions of high density lipoproteins (HDL) which contain either apolipoprotein (apo) A-I or apoE as their only apolipoproteins. From these initial acceptors, which are termed pre $\beta_{1}-L p A-I$ and $\gamma$-LpE, respectively, cell-derived cholesterol is transferred to LDL via the bulk of HDL termed $\alpha$-LpA-I. In this study we analyzed the effect in plasma of the genetically determined apoE polymorphism on the formation of $\gamma-\mathrm{LpE}$, uptake and transfer of cell-derived cholesterol to LDL. $\gamma$-LpE was immunologically detectable in plasmas of individuals carrying at least one apoE3-allele but not in apoE3-free plasmas. During one minute incubation with $\left[{ }^{3} \mathbf{H}\right]$ cholesterol-labeled fibroblasts, $\gamma$-LpE of plasmas from apoE3/3 subjects accumulated 7and 13-fold more radioactivity than the respective fractions in plasmas from apoE2/2- and apoE4/4-subjects, respectively. Totally, $30 \%$ less $\left[{ }^{3} \mathrm{H}\right]$ cholesterol was released into plasmas of apoE2/2 and apoE4/4-individuals as compared with plasmas of apoE3/3-subjects. Moreover, plasmas of apoE3/3 individuals accumulated $50 \%$ and $65 \%$ more cellderived $\left[{ }^{3} \mathrm{H}\right]$ cholesterol in $\alpha-\mathrm{LpA}-\mathrm{I}_{2}$ than plasmas of apoE4/ 4 and apoE2/2-subjects, respectively. These results indicate that the apoE-polymorphism is an important determinant of the uptake and transfer of cell-derived cholesterol in plasma. (J. Clin. Invest. 1995. 96:2693-2701.) Key words: HDL-subclasses • reverse cholesterol transport • arteriosclerosis
\end{abstract}

\section{Introduction}

Apolipoprotein (apo) E is genetically polymorphic. Three common alleles of the apoE gene encode for three apoE isoforms, designated apoE3, apoE4, and apoE2. The rarer isoforms apoE4 and apoE2 differ from apoE3 by the presence of an arginine instead of a cysteine at residue 112 and a cysteine instead of an arginine at residue 158 (reviewed in references 1 and 2 ).

Address correspondence to Arnold von Eckardstein, Institut für Klinische Chemie und Laboratoriumsmedizin, Zentrallaboratorium, Westfälische Wilhelms-Universität Mänster, Albert-Schweitzer-Strasse 33, D48129 Münster, Federal Republic of Germany. Phone: 251-837222; FAX: 251-837225.

Received for publication 13 September 1994 and accepted in revised form18 August 1995.

J. Clin. Invest.

(C) The American Society for Clinical Investigation, Inc. 0021-9738/95/12/2693/09 \$2.00

Volume 96, December 1995, 2693-2701
Compared with apoE3, apoE4 is associated with higher levels of low density lipoprotein (LDL) -cholesterol and with increased risk for myocardial infarction. By contrast, in several studies the apoE2-allele was found to decrease LDL-cholesterol and cardiovascular risk (reviewed in references 2 and 3 ). The metabolic basis for these differences is not entirely understood but has usually been explained by the role of apoE in the trafficking of lipids between various organs (reviewed in reference 1). As a structural component of very low density lipoproteins (VLDL), apoE helps to direct triglycerides from the liver to peripheral tissues. Hydrolysis of endogenously synthesized triglycerides in VLDL and of dietary fat in chylomicrons generates remnants which are rich in cholesteryl esters and contain apoE. These particles are internalized and degraded mainly by hepatocytes after apoE-mediated binding to the LDL-receptor or the remnant-receptor (reviewed in references 1,4 , and 5). Since apoE2 is considerably reduced in its affinity to bind to these receptors, remnant uptake into the liver is decreased (6). As a regulatory response, activity of LDL-receptors is increased and thereby apoB-mediated removal of LDL enhanced $(2,7)$. This may explain the LDL-cholesterol lowering and possibly antiatherogenic effects of apoE2. ApoE4, however, binds normally to LDL- and remnant receptors (6). The LDL-cholesterol increasing effect of apoE4 has usually been explained by the increased affinity of apoE4 for triglyceride-rich lipoproteins which enhances their elimination, thereby down-regulating LDL-receptor gene expression and thus increasing the plasma concentration of LDL-cholesterol $(7,8)$.

However, some evidence indicates that the effect of apoE and its polymorphic variability on atherosclerosis is independent of its effect on the regulation of LDL-receptor activity. At least one study found that apoE4 is associated with increased cardiovascular risk independent of the level of LDL-cholesterol (9). Infusion of apoE in LDL-receptor-negative Watanabe hyperlipidemic rabbits significantly decreases the progression of atherosclerosis (10). The latter observation accounts for an anti-atherogenic role of apoE which may be due to its involvement in the reverse transport of cholesterol from peripheral cells to the liver (reviewed in references 1 and 11-13). For example, apoE is produced by macrophages which have been loaded with cholesterol. In the presence of HDL, apoE secretion by macrophages enhances cholesterol efflux $(14,15)$. Moreover, apoE is present in some HDL which can therefore be eliminated by apoE- and apoB,E-receptors (16-18). Finally, we have recently identified a plasma lipoprotein in which apoE constitutes the only apolipoprotein and which is an initial acceptor of cellderived cholesterol in the plasma compartment (19). Because of its electrophoretic mobility, this lipoprotein is termed $\gamma$ lipoprotein $\mathrm{E}(\mathrm{LpE}) .^{1}$ This role of initial acceptor of cell-de-

1. Abbreviations used in this paper: LpA-I, lipoprotein A-I; LpE, lipoprotein $\mathrm{E}$. 
Table I. Characteristics of the Individuals whose Plasmas Were Analyzed by 2D-PAGGE

\begin{tabular}{|c|c|c|c|c|c|c|c|}
\hline apoE-phenotype & Cholesterol & Triglycerides & LDL-chol. & HDL-chol. & ApoA-I & Plasma apoE & HDL-apoE \\
\hline \multicolumn{8}{|c|}{$m g / d l$} \\
\hline $3 / 3(n=6)$ & $212 \pm 47$ & $111 \pm 36$ & $133 \pm 33$ & $58 \pm 21$ & $151 \pm 45$ & $2.22 \pm 0.66$ & $0.70 \pm 0.27$ \\
\hline $2 / 2(n=5)$ & $249 \pm 49$ & $194 \pm 83$ & $165 \pm 45$ & $45 \pm 12$ & $141 \pm 17$ & $12.62 \pm 7.00$ & $2.52 \pm 1.06$ \\
\hline $4 / 4(n=5)$ & $212 \pm 16$ & $123 \pm 37$ & $146 \pm 16$ & $42 \pm 9$ & $115 \pm 18$ & $1.39 \pm 0.61$ & $0.42 \pm 0.07$ \\
\hline $3 / 2(n=4)$ & $206 \pm 42$ & $129 \pm 45$ & $133 \pm 37$ & $47 \pm 21$ & $138 \pm 42$ & $3.91 \pm 1.81$ & $1.06 \pm 0.23$ \\
\hline $3 / 4(n=5)$ & $255 \pm 62$ & $121 \pm 84$ & $174 \pm 46$ & $57 \pm 29$ & $155 \pm 45$ & $3.88 \pm 1.91$ & $0.82 \pm 0.04$ \\
\hline $4 / 2(n=3)$ & $233 \pm 32$ & $196 \pm 64$ & $160 \pm 22$ & $33 \pm 2$ & $118 \pm 14$ & $7.03 \pm 1.50$ & $1.52 \pm 0.36$ \\
\hline
\end{tabular}

Data are mean values of the samples analyzed by 2D-PAGGE and subsequent anti-apoE- and apoA-I immunoblotting.

rived cholesterol into the plasma compartment was formerly ascribed to a purely apoA-I containing lipoprotein termed $\operatorname{pre} \beta_{1^{-}}$ LpA-I which has electrophoretic pre $\beta$-mobility (20). $\operatorname{Pre} \beta_{1^{-}}$ LpA-I and $\gamma$-LpE are minor subfractions of HDL. They can be separated from the bulk of HDL, i.e. that containing apoA-I and showing $\alpha$-mobility, $\alpha$-LpA-I, by two-dimensional electrophoresis using agarose gel electrophoresis followed by nondenaturing polyacrylamide gradient gel electrophoresis $(20-22)$. Cholesterol taken up by pre $\beta_{1}$-LpA-I is transferred to LDL via two other HDL-fractions with pre $\beta$-mobility, namely pre $\beta_{2}$ LpA-I and pre $\beta_{3}$-LpA-I, and $\alpha$-LpA-I (21). A small amount of cholesterol is esterified in pre $\beta_{3}$-LpA-I which contains CETP, LCAT and apoD $(21,23)$. Most of the cholesterol is esterified in $\alpha$-LpA-I after re-transfer from LDL (21). It is not known by which route cholesterol is transferred from $\gamma$ - $\mathrm{LpE}$ among plasma lipoproteins.

Because of its role in reverse cholesterol transport and because of the findings in a recent meta-analysis that apoE4 decreases HDL-cholesterol (24), we investigated whether plasmas with different apoE isoforms differ by their ability to form $\gamma$ $\mathrm{LpE}$, and to take up, transfer and esterify cell-derived cholesterol.

\section{Methods}

Subjects and plasma samples. 28 probands with different apoE phenotypes participated in this study. Characteristics of their lipid metabolism are summarized in Table I. Blood samples were collected after overnight fasting and were cooled immediately on ice. Plasmas and sera were obtained by centrifugation at $4^{\circ} \mathrm{C}(2,000 \mathrm{~g}, 15 \mathrm{~min})$, aliquoted and frozen at $-70^{\circ} \mathrm{C}$. Serum was used for the quantification of lipids. EDTAplasma was used for the immunological demonstration of HDL-subclasses. For experiments in which plasmas were incubated with cells, streptokinase was used as the anticoagulant at a final concentration of $150 \mathrm{U} / \mathrm{ml}$ blood.

Quantification of lipids and apolipoproteins. Serum concentrations of triglycerides and cholesterol were quantified with an autoanalyzer (Hitachi/Boehringer, Mannheim, FRG). HDL-cholesterol concentrations were measured after precipitation of apoB containing lipoproteins with phosphotungstic acid/ $\mathbf{M g C l}_{2}$ (Boehringer, Mannheim, FRG). LDL-cholesterol was calculated using the Friedewald formula (25).

Concentrations of apoA-I and apoB were determined with a modified commercially available turbidimetric immunoassay (Boehringer Mannheim, FRG) (26)

ApoE levels were measured by the use of a sandwich-enzymeimmunoassay in total serum (dilution: 1/4000) as well as in the supernatant obtained after precipitation of apoB-containing lipoproteins with phosphotungstic acid/ $\mathrm{MgCl}_{2}$ (Boehringer, Mannheim, FRG) (dilution: 1/
1000). IgG of a polyclonal goat anti-apoE-antiserum (Boehringer Mannheim) were coated to microtiter plates to be used as capture antibodies. A labmade rabbit anti-apoE-antiserum was used as the second antibody. The antigen-antibody-reaction was visualized by the use of a peroxidaselabeled donkey anti-rabbit-IgG-antiserum and 1,2-phenylenediamine and $\mathrm{H}_{2} \mathrm{O}_{2}$ as substrates. The assay was calibrated with a dilution series of a serum with known apoE-concentration. The intra- and interassay coefficients of variation were below 10 and $15 \%$, respectively.

Determination of apolipoprotein $E$ phenotype. The apoE polymorphism was determined as a phenotype by IEF of serum which was treated with neuraminidase and delipidated with ethanol:ether (3:1) (27). Subsequent to Western Blotting onto nitrocellulose membranes, apoE isoforms were detected by the use of polyclonal goat antibodies against human apoE (Boehringer Mannheim, FRG), and peroxidaseconjugated antibodies against goat IgG (DAKO GmbH, Hamburg, FRG).

Nondenaturing two-dimensional electrophoresis. The distribution of apoA-I- and apoE-containing lipoproteins in plasma was determined by nondenaturing two-dimensional electrophoresis where agarose gel electrophoresis was followed by nondenaturing polyacrylamide gradient gel electrophoresis (PAGGE) (21). Briefly, in the first dimension, 30 $\mu \mathrm{l}$ of plasma samples were separated by electrophoresis at $4^{\circ} \mathrm{C}$ in a $0.75 \%$ agarose gel using a $50 \mathrm{mM}$ merbital buffer at pH 8.6 (Serva, Heidelberg, FRG). Agarose gel strips containing the pre-separated lipoproteins were then transferred to a 3-20\% polyacrylamide gradient gel. Separation in the second dimension was performed at $40 \mathrm{~mA}$ for 4$5 \mathrm{~h}$ at $10^{\circ} \mathrm{C}$. After separation, the proteins in the PAGGE gels were electroblotted onto a nitrocellulose membrane. ApoA-I- and apoE-containing lipoproteins were subsequently detected by the use of sheep antibodies against human apoA-I or apoE (Boehringer Mannheim), respectively, which had been biotinylated following the manufacturer's recommendations (Sigma, Heidelberg, FRG), and streptavidin-biotinylated horseradish peroxidase complex (Amersham Buchler GmbH, Braunschweig, FRG). The lower detection limit of this visualization method was established by SDS-PAGE (28) and subsequent anti-apoEimmunoblotting of a dilution series of serum with known apoE-concentration. By this method we also ruled out cross-reactivities of this antibody with other plasma proteins.

Alternatively, we visualized apoE-containing lipoproteins by the use of two different lab-made rabbit antisera against human apoE, biotinylated anti-rabbit IgG antibodies from pig (DAKO), and horseradishperoxidase. In some experiments we used radioiodinated anti-rabbit IgG (Amersham) as the second antibody to visualize apoE-containing lipoproteins on Western blots by autoradiography.

Cell culture. Normal human skin fibroblasts were cultured in Dulbecco's modified Eagle's medium (DME) containing $10 \%$ fetal calf serum in dishes with $3.5 \mathrm{~cm}$ diameter as described previously (21). At the state of near confluence, cells of some dishes were labeled for 72 $\mathrm{h}$ at $37^{\circ} \mathrm{C}$ with $0.5 \mathrm{mCi}\left(1,2-{ }^{3} \mathrm{H}\right)$-cholesterol $(51.7 \mathrm{Ci} / \mathrm{mmol}$; New England Nuclear, Boston, MA), which had been complexed with fetal calf serum. The final specific radioactivity in the labeled cells amounted to $1.4 \pm 0.4 \times 10^{7} \mathrm{cpm} / \mu \mathrm{g}$ cell unesterified cholesterol (mean $\left.\pm \mathrm{SD}\right)$. 
Pulse-chase incubations with fibroblasts. Fibroblasts labeled with radiolabeled cholesterol were washed six times with serum free DME before incubations. In pulse-chase experiments, $1 \mathrm{ml}$ of plasma was first incubated with radiolabeled fibroblasts for $1 \mathrm{~min}$ (pulse). After incubation, the plasma was removed and then used for chase incubations for another $1 \mathrm{~min}$ which were performed in the absence of cells. After pulse or chase incubations, aliquots of the plasma samples were separated by nondenaturing 2D-PAGGE. 2D-PAGGE was performed in parallel on a radiolabeled and a nonradiolabeled sample. After separation, one half of the PAGGE gel containing the radiolabeled sample was first stored at $4^{\circ} \mathrm{C}$. The other half of the gel containing the nonradiolabeled sample was electroblotted onto a nitrocellulose membrane to identify lipoproteins containing apoA-I and apoE, respectively. The immunoblot was then used as a template to localize the corresponding lipoproteins in the other half of the gel. These lipoproteins were cut out, and their lipids were extracted by chloroform/methanol $(2: 1, \mathrm{vol} / \mathrm{vol})$ for $72 \mathrm{~h}$ (28). Since $\gamma$-LpE was not immunodetectable in plasmas of apoE2/2and apoE4/4-individuals (see results), we used anti-apoE-immunoblots of 2D-electropherograms of apoE3-containing plasmas for the localization of $\gamma$-LpE-like particles in these plasmas. Every plasma sample was analyzed three times in independent experiments. The interassay-coefficients of variation in the recovery of radioactivity in the various lipoproteins ranged between 16 and $23 \%$. In some instances, percent values are presented. They represent the amount of $\left[{ }^{3} \mathrm{H}\right]-$ cholesterol in one particle as a percentage of total $\left[{ }^{3} \mathrm{H}\right]$ cholesterol in all lipoproteins ( $=\gamma$-LpE + pre $\beta$-LpA-I $+\alpha$-LpA-I + LDL $)$.

Digestion with phospholipase $C$ or sphingomyelinase. To determine the effects of phospholipids on the distribution of apoE in various lipoproteins, $100 \mu \mathrm{l}$ plasma were incubated with 8 units of phosphatidylcholine-specific phospholipase C from Bacillus cereus (Sigma) or with 5 units of sphingomyelinase from Bacillus cereus (Boehringer Mannheim, FRG) for $10 \mathrm{~h}$ at $37^{\circ} \mathrm{C}$. These pre-treated samples were used for 2DPAGGE.

Statistical analyses. Statistical analyses were performed by the use of the Statistical Package for the Social Sciences (SPSS). Student's $t$ test was used for the comparison of mean values. Pearson's test was used for regression analyses.

\section{Results}

Distribution of apoE- and apoA-I-containing lipoproteins in plasmas with different apoE phenotypes. Fig. 1 demonstrates representative anti-apoE-immunoblots of lipoproteins in plasmas of individuals with different apoE phenotypes which have been separated by nondenaturing 2D-PAGGE. ApoE-containing lipoproteins have been visualized with biotinylated, polyclonal anti-apoE-antibodies and streptavidin-conjugated horseradishperoxidase. The lower detection limit of this visualization method was $<0.15 \mathrm{ng}$ apoE. Plasmas of individuals with apoE3/3 contained anti-apoE-immunoreactive material in LDL as well as in particles with electrophoretic $\alpha$-mobility (i.e., $\alpha$ $\mathrm{LpE}$ ), $\beta$-mobility (i.e., $\beta$-LpE), and $\gamma$-mobility (i.e., $\gamma$-LpE). Plasmas of individuals with the other five apoE-phenotypes also contained apoE in LDL and the $\alpha$-migrating particle. The amount of apoE in these fractions, however, varied between individuals depending on their apoE phenotype. In keeping with HDL-apoE levels, the highest amounts of $\alpha$-LpE were found in plasmas of individuals with apoE2/2, the lowest amounts in plasmas of homozygotes for apoE4. $\beta$-LpE was also visible in all plasmas, the highest amounts in plasmas of apoE2 homozygotes, the lowest amounts in samples of individuals with the phenotypes apoE4/4 or apoE4/3. $\gamma$-LpE was immunologically detectable only in plasmas of individuals who had the phenotypes apoE3/3, apoE3/2, and apoE3/4 but not in samples of individuals with the phenotypes apoE2/2, apoE4/4, and apoE4/
2. Immunodetection of $\gamma-\mathrm{LpE}$ was independent of the apoE concentration in either plasma or HDL. $\gamma-\mathrm{LpE}$ was found in the sample of an apoE4/3-heterozygote who had very low apoE levels in both plasma $(1.65 \mathrm{mg} / \mathrm{dl})$ and $\mathrm{HDL}(0.35 \mathrm{mg} / \mathrm{dl})$ but not in the samples of an apoE4/4 homozygote with similarly low apoE concentrations (plasma, $1.8 \mathrm{mg} / \mathrm{dl}$; HDL, $0.33 \mathrm{mg} /$ dl) or in the sample of an apoE2/2-homozygote with very high apoE-levels (plasma, $23.75 \mathrm{mg} / \mathrm{dl}$; HDL, $4.32 \mathrm{mg} / \mathrm{dl}$ ). Alternatively, we used two different rabbit antisera raised against human apoE to detect apoE-containing lipoproteins in Western blots of 2D-electropherograms. Visualization of the immunoreactions by the use of either biotinylated anti-rabbitIgG antibodies and streptavidin-horseradish peroxidase or radioiodinated anti-rabbit-IgG antibodies detected $\gamma$-LpE in plasmas containing apoE3 but not in plasmas of homozygotes for apoE4 or apoE2 (not shown).

Anti-apoA-I immunoblotting revealed no qualitative differences in the distribution of apoA-I-containing lipoproteins between plasmas from donors with the various apoE phenotypes (Fig. $2 a$ ). All plasmas contained pre $\beta_{1}$-LpA-I, pre $\beta_{2}$-LpA-I, and $\alpha$-LpA-I. Relative amounts of $\alpha$-LpA-I $\mathrm{I}_{3}$ and $\alpha$-LpA-I $\mathrm{I}_{2}$ varied interindividually but were independent of the apoE-phenotype (not shown). Pre $\beta_{3}$-LpA-I was not immunodetectable in every sample but this also was independent of the apoE-phenotype.

Effects of digestion with phosphatidlycholine-specific phospholipase $C$ or sphingomyelinase on the distribution of apoEand apoA-I-containing lipoproteins. Incubation of plasma with phosphatidylcholine-specific phospholipase C (PC-PLC) or sphingomyelinase leads to specific digestion of lipoproteins and thereby to specific changes in their electrophoretic appearance (Figs. 2 and 3). Digestion with either PC-PLC or sphingomyelinase destroys $\alpha$-LpA-I and causes the accumulation of antiapoA-I immunoreactive material in a fraction with the electrophoretic mobility of pre $\beta_{1}$-LpA-I (Fig. $2, b$ and $c$ ). Presumably due to its high content in sphingomyelin (19), $\gamma$-LpE was digested by sphingomyelinase but not by PC-PLC (Fig. 3, a and $d$ ). After incubation of plasmas of apoE3/3-individuals with PC-PLC, $\alpha$-LpE but not $\gamma$-LpE was destroyed (Fig. $3 a$, see Fig. 1). The absence of other lipoproteins rather facilitated the immunodetection of $\gamma$-LpE. We used this phenomenon to attempt to provoke immunodetection of $\gamma-\mathrm{LpE}$ in plasmas of homozygotes for apoE2 and apoE4. However, even after digestion with PC-PLC, $\gamma$-LpE remained undetectable in these plasmas (Fig. 3, $b$ and $c$ ). Surprisingly, some other lipoproteins in plasmas of apoE2/2- and apoE4/4-homozygotes resisted digestion with PC-PLC.

Effects of apoE phenotypes on the uptake of cell-derived cholesterol by plasma and HDL-subclasses. To investigate the effect of the apoE polymorphism on uptake and transfer of cellderived cholesterol by total plasma and various lipoproteins, plasmas of homozygotes for either apoE2, apoE3, or apoE4 were pulse/chase-incubated with radiolabeled fibroblasts. The effect of the apoE polymorphism on cholesterol efflux stimulation by total plasma was measured as the efflux of $\left[{ }^{3} \mathrm{H}\right]-$ cholesterol from labeled fibroblasts into plasma during a 1min incubation. Plasmas of homozygotes for apoE4 and apoE2 exhibited a $30 \%$ lower ability to release $\left[{ }^{3} \mathrm{H}\right]$ cholesterol from fibroblasts than plasmas of apoE3/3-individuals (Table III, $P$ $<0.05$, student's $t$ test ).

For a more detailed analysis of $\left[{ }^{3} \mathrm{H}\right]$ cholesterol efflux into HDL-subfractions, pulse and chase incubations of plasmas were 


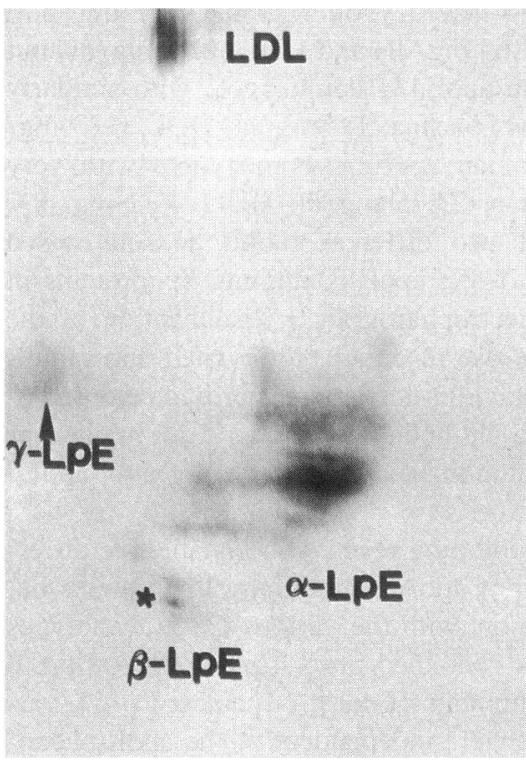

E4/4

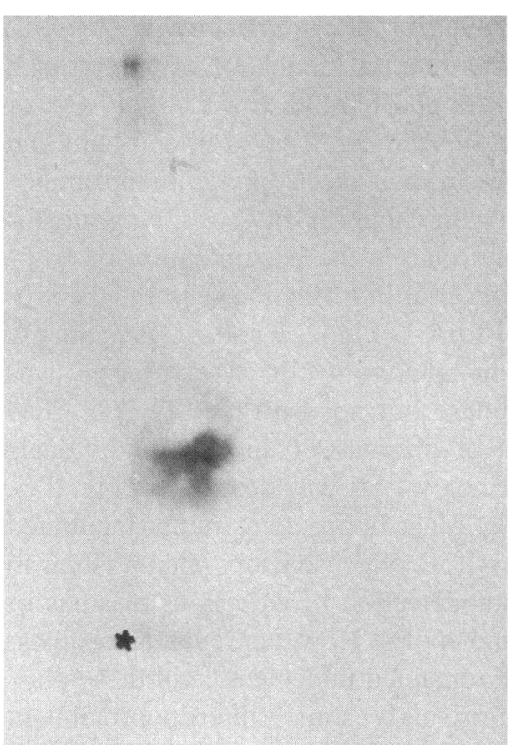

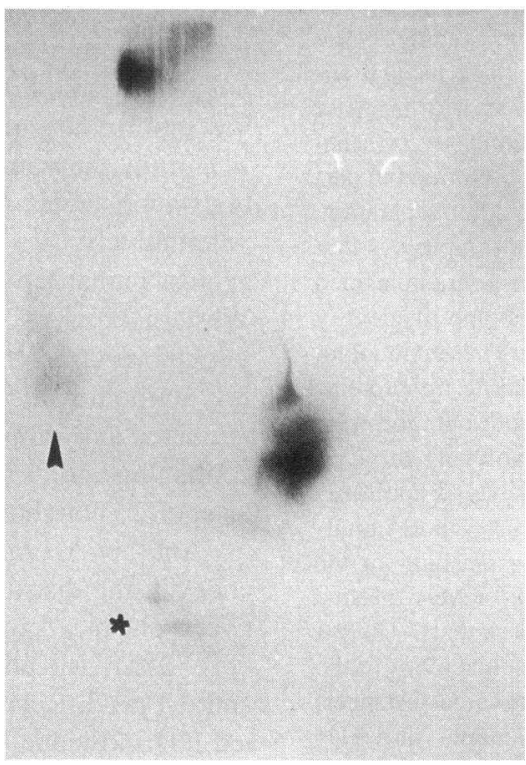

$E 2 / 2$

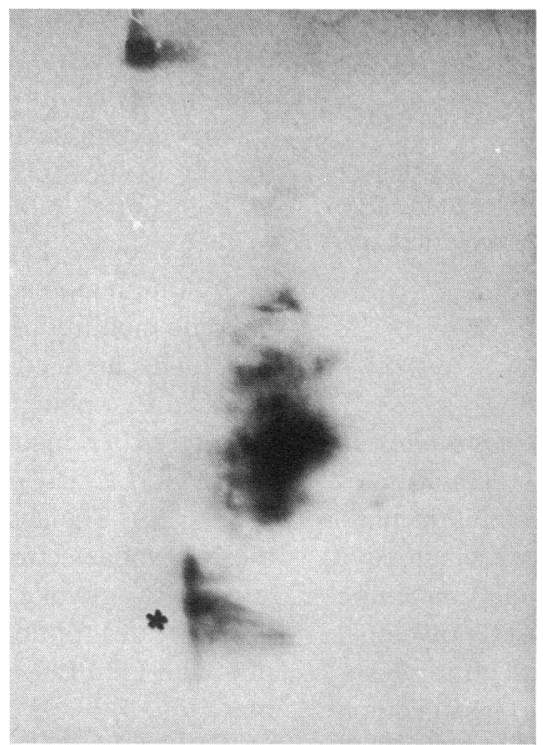

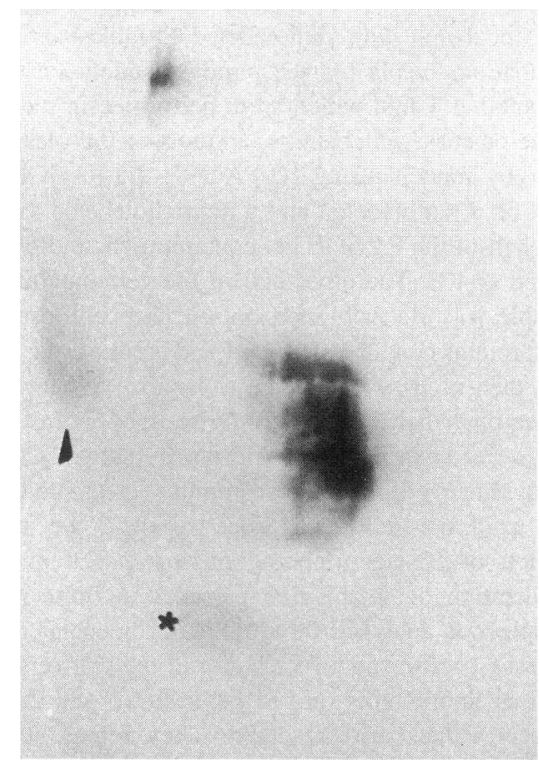

$E 4 / 2$

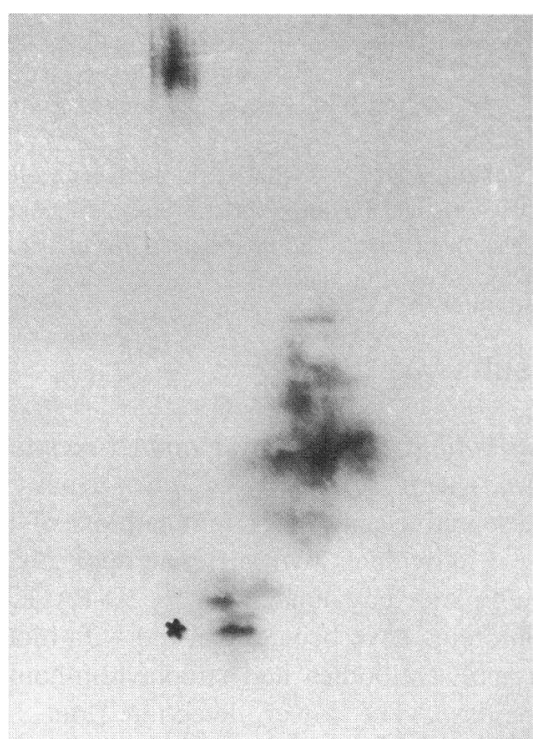

Figure 1. Distribution of apoE-containing lipoproteins in the plasma of individuals with different apoE polymorphisms as detected by 2D-PAGGE. $30 \mu \mathrm{l}$ plasma were separated by 2D-PAGGE in the sequence agarose gel electrophoresis-nondenaturing polyacrylamide gradient gel electrophoresis. After electrophoresis, proteins were electroblotted onto nitrocellulose membranes. ApoE-containing lipoproteins were detected by the use of polyclonal sheep anti-human apoE antibodies (Boehringer Mannheim), which had been biotinylated according to the manufacturer's recommendations (Sigma). Antigen-antibody complexes were visualized by the use of a streptavidin-biotinylated horseradish peroxidase complex (Amersham). The position of $\gamma$-LpE is marked with arrows, the position of $\beta$-LpE with asterisks. Note the presence of $\gamma$-LpE in plasmas from subjects with apoE3/3 (serum apoE, $1.75 \mathrm{mg} / \mathrm{dl}$; HDL-apoE, $1.14 \mathrm{mg} / \mathrm{dl}$ ), apoE4/3 (serum apoE, $1.69 \mathrm{mg} / \mathrm{dl}$; HDL-apoE, $0.35 \mathrm{mg} / \mathrm{dl}$ ), and apo E3/2 (serum apoE, $2.36 \mathrm{mg} / \mathrm{dl}$; HDL-apoE, $1.27 \mathrm{mg} / \mathrm{dl}$ ) but absence in plasmas from subjects with apoE4/4 (serum apoE, $1.81 \mathrm{mg} / \mathrm{dl}$; $\mathrm{HDL}-\mathrm{apoE}, 0.33 \mathrm{mg} /$ dl), apoE2/2 (serum apoE, $9.23 \mathrm{mg} / \mathrm{dl}$; HDL-apoE, $2.24 \mathrm{mg} / \mathrm{dl}$ ), and apoE4/2 (serum apoE, $8.41 \mathrm{mg} / \mathrm{dl} ; \mathrm{HDL}-\mathrm{apoE}, 1.20 \mathrm{mg} / \mathrm{dl}$ ).

followed by 2D-PAGGE. Anti-apoA-I- and anti-apoE-immunoblots of 2D-electropherograms of apoE3/3-plasma were used as templates to localize apoA-I- and apoE-containing lipoproteins in the gels. $\alpha$-LpA-I was divided into $\alpha$-LpA-I $\mathrm{I}_{3}$ and $\alpha$ LpA- ${ }_{2}$ with Stokes diameters of 7.5-9.5 and 9.6-12.0 nm, respectively. $\alpha$-LpE was not considered separately, since it was almost entirely colocalized with $\alpha$-LpA-I,$\beta$-LpE was also not considered since it contained only trace amounts of radioactivity after both pulse- and chase-incubations. Each of the six plasmas (two for each phenotype) was analyzed in three independent 

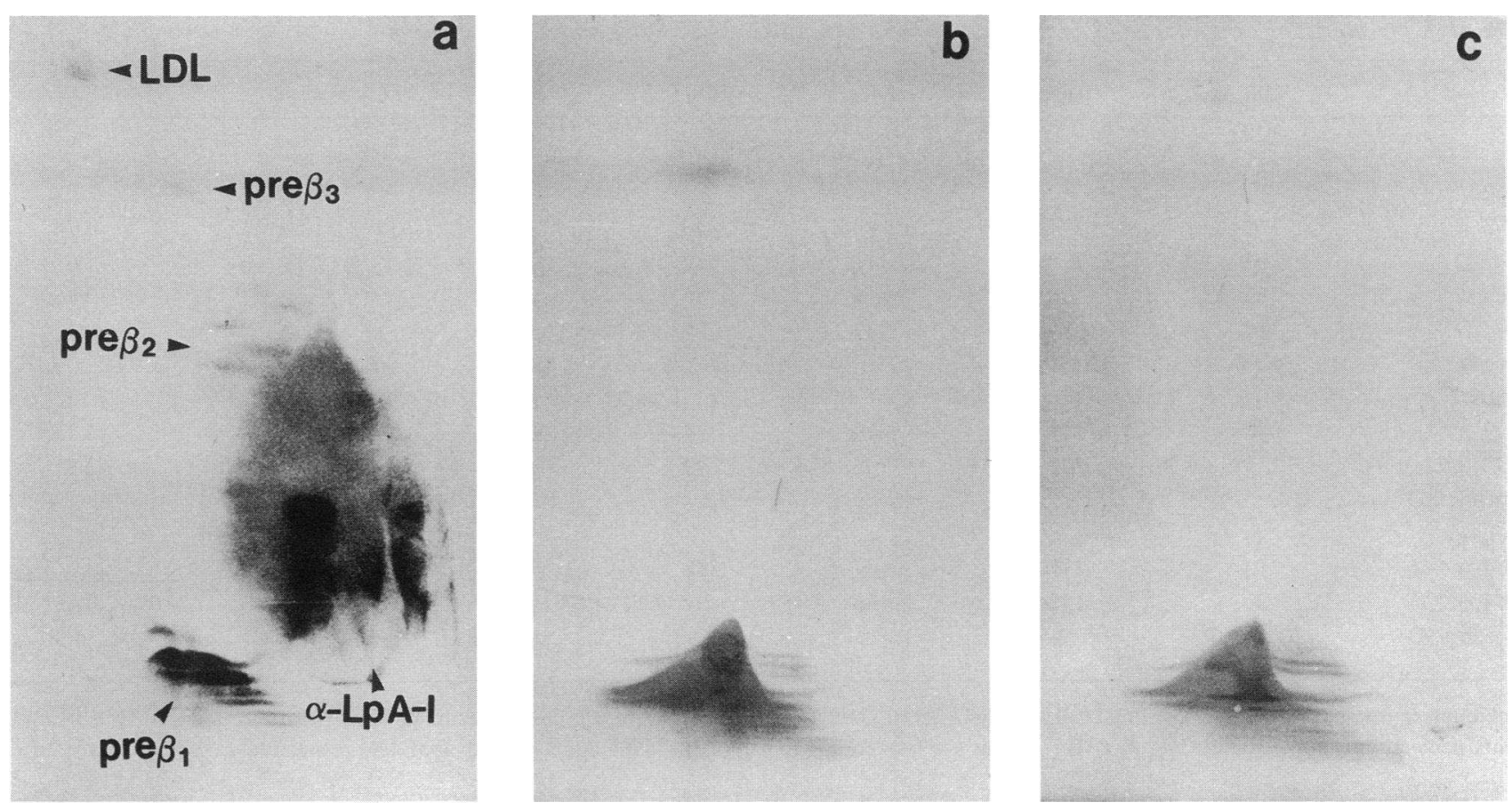

Figure 2. Distribution of apoA-I-containing lipoproteins. Electrophoretic procedures were as described in Fig. 1. ApoA-I was detected by the use of a polyclonal anti-apoA-I antiserum from sheep (Boehringer Mannheim) which had been biotinylated and were visualized as described for Fig. 1. $a$ shows the distribution of apoA-I containing lipoproteins in native plasma, $b$ and $c$ their distribution in plasmas which had previously been incubated with phosphatidylcholine-specific phospholipase $\mathrm{C}$ and sphingomyelinase, respectively. The apoE polymorphism had no effect on the distribution of apoA-I containing lipoproteins in native or pretreated samples.

series of experiments. Among these triplicate analyses, the interassay variation in the recovery of radioactivity in the various lipoproteins ranged between 16 and $23 \%$. The recoveries of radioactivity extracted from the lipoproteins, i.e., $\gamma$-LpE, pre $\beta_{1}$ LpA-I, $\alpha$-LpA-I $\mathrm{I}_{2}, \alpha$-LpA-I $\mathrm{I}_{3}$ and LDL, ranged from 70 to $80 \%$ and did not differ significantly between plasmas with different apoE phenotypes. This recovery is lower than reported pre- viously (30) since we did not consider pre $\beta_{2}$-LpA-I and pre $\beta_{3^{-}}$ LpA-I.

After 1-min pulse of plasmas from individuals with apoE3/ 3 (Table III), the percentages of $\left[{ }^{3} \mathrm{H}\right]$ cholesterol in $\gamma$-LpE, pre $\beta_{1}$-LpA-I, $\alpha$-LpA-I ${ }_{3}, \alpha-\mathrm{LpA}-\mathrm{I}_{2}$ and LDL amounted to $19 \pm 5$, $6 \pm 1,26 \pm 8,25 \pm 8$, and $23 \pm 7 \%$, respectively. During the subsequent one-minute chase, radioactivity in $\gamma$-LpE and pre $\beta_{1}$-LpA-
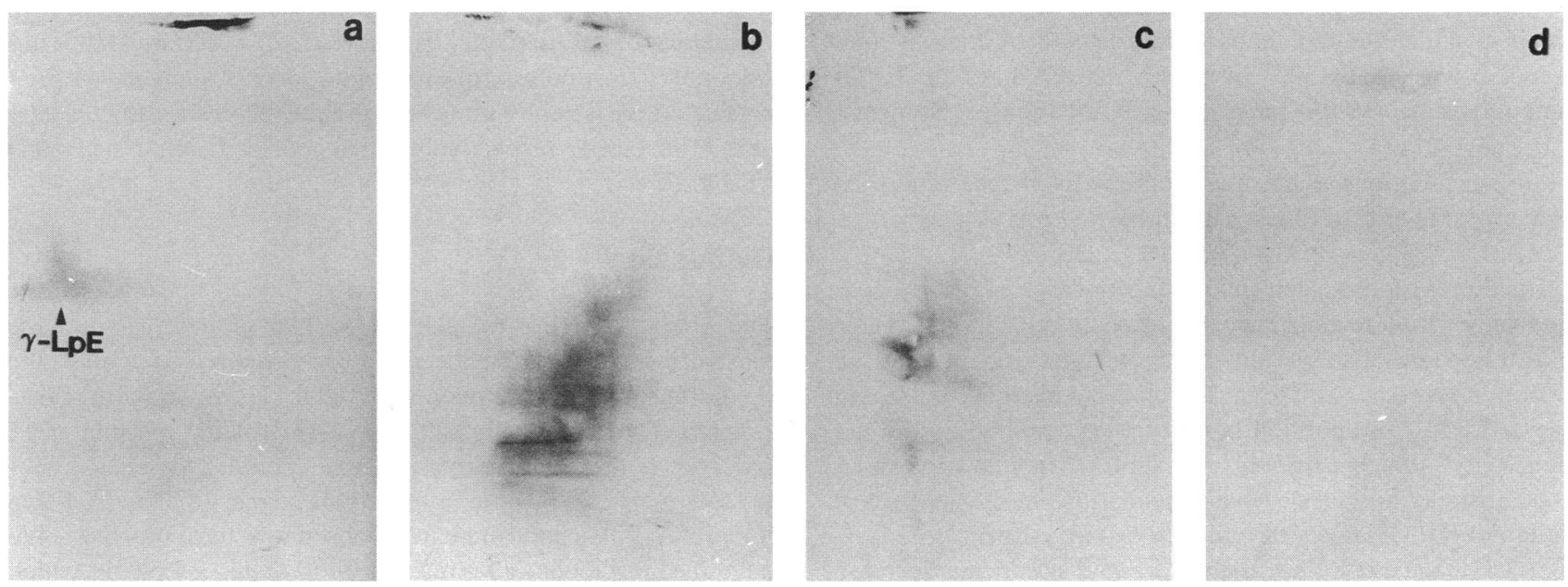

Figure 3. Effect of the apoE polymorphism on the distribution of apoE containing lipoproteins in plasmas which have been treated with phopsholipase $\mathrm{C}$ and sphingomyelinase. Electrophoretic procedures were as described in Fig. 1. $a-c$ demonstrate the occurrence of apoE containing lipoproteins in plasmas which have been incubated with phosphatidylcholine specific phospholipase C (PC-PLC). $d$ shows the effect of incubation with sphingomyelinase. Note the resistance of $\gamma$-LpE in the plasma of the homozygote for apoE3 towards digestion with PC-PLC ( $a$ ) but absence of $\gamma$-LpE in the plasma of probands with apoE2/2 $(b)$ or apoE4/4 (c). In all cases, digestion with sphingomyelinase eliminated all apo E-containing lipoproteins $(d)$. 
Table II. Characteristics of the Individuals whose Plasmas Were Analyzed by Pulse-Chase Experiments

\begin{tabular}{|c|c|c|c|c|c|c|c|}
\hline Subjects & Chol. & Trig. & LDL-C. & HDL-C. & ApoA-I & pI. apoE & HDL-apoE \\
\hline \multicolumn{8}{|c|}{ mgdl } \\
\hline \multicolumn{8}{|l|}{ ApoE3/3 } \\
\hline 3/3-A & 141 & 77 & 88 & 40 & 123 & 1.50 & 0.70 \\
\hline $3 / 3-B$ & 203 & 118 & 112 & 72 & 139 & 2.19 & 0.61 \\
\hline $3 / 3-C$ & 263 & 92 & 160 & 85 & 219 & 3.19 & 0.66 \\
\hline $3 / 3-\mathrm{D}$ & 175 & 74 & 133 & 27 & 107 & 3.33 & 0.44 \\
\hline mean \pm SD & $196 \pm 52$ & $90 \pm 20$ & $123 \pm 30$ & $56 \pm 27$ & $152 \pm 47$ & $2.55 \pm 0.87$ & $0.60 \pm 0.11$ \\
\hline \multicolumn{8}{|l|}{ ApoE2/2 } \\
\hline $2 / 2-\mathrm{A}$ & 306 & 312 & 210 & 34 & 136 & 23.75 & 4.32 \\
\hline 2/2-B & 238 & 157 & 158 & 49 & 166 & 9.23 & 2.24 \\
\hline mean $\pm \mathrm{SD}$ & $272 \pm 48$ & $234 \pm 110^{*}$ & $184 \pm 37$ & $42 \pm 11$ & $151 \pm 23$ & $16.5 \pm 10.3^{* *}$ & $3.28 \pm 1.47 * *$ \\
\hline \multicolumn{8}{|l|}{ ApoE4/4 } \\
\hline $4 / 4-\mathrm{A}$ & 210 & 177 & 147 & 28 & 89 & 2.02 & 0.41 \\
\hline 4/4-B & 189 & 142 & 128 & 32 & 102 & 1.39 & 0.42 \\
\hline mean $\pm S D$ & $200 \pm 15$ & $160 \pm 25$ & $138 \pm 13$ & $30 \pm 3$ & $96 \pm 9$ & $1.71 \pm 0.45$ & $0.42 \pm 0.01$ \\
\hline
\end{tabular}

Chol, cholesterol; Trig, triglycerides; $L D L-C$, LDL-cholesterol; HDL-C, HDL-cholesterol; pl. apoE, plasma-apoE; HDL-apoE, apoE in HDL; $C P M$, counts per minute. ${ }^{*} P<0.05$;** $P<0.01$; student's $t$ test comparing apoE3/3 with apoE2/2 and apoE4/4, respectively.

I decreased to $4 \pm 1$ and $2 \pm 1 \%$, and simultaneously increased in $\alpha-\mathrm{LpA}-\mathrm{I}_{3}, \alpha-\mathrm{LpA}-\mathrm{I}_{2}$ and $\mathrm{LDL}$ to $32 \pm 6,30 \pm 5$, and $32 \pm 6 \%$, respectively. These results indicate that in plasmas of apoE3/ 3 -subjects, both $\gamma$-LpE and pre $\beta_{1}$-LpA-I serve as initial acceptors of cell-derived cholesterol.

Plasmas of apoE2/2-individuals incorporated $4 \pm 1 \%$ of cellderived $\left[{ }^{3} \mathrm{H}\right]$ cholesterol into a fraction with the electrophoretic properties of $\gamma$-LpE, $8 \pm 2 \%$ into pre $\beta_{1}-\mathrm{LpA}-\mathrm{I}, 39 \pm 7 \%$ into $\alpha-$ LpA- $\mathrm{I}_{3}, 21 \pm 6 \%$ into $\alpha$-LpA-I $\mathrm{I}_{2}$, and $27 \pm 7 \%$ into LDL (Table III). The radioactivity taken up by the $\gamma$-LpE-like particle in the plasma of apoE2/2-homozygotes was $14 \%$ of that in $\gamma$ - $\mathrm{LpE}$ of apoE3/3-individuals $(P<0.001$, Student's $t$ test $)$. During subsequent chase, the radioactivity in $\gamma$-LpE and pre $\beta_{1}$-LpA-I decreased to 1 and $2 \%$, respectively. The percent radioactivity in $\alpha$-LpA- $\mathrm{I}_{3}$ and $\alpha$-LpA-I $\mathrm{I}_{2}$ remained nearly unchanged and simultaneously increased in LDL from $27 \pm 7$ to $41 \pm 10 \%$. After both pulse and chase, radioactivity in $\alpha$-LpA- $\mathrm{I}_{2}$ of homozygotes for apoE2 was about $50 \%$ of that in $\alpha-\mathrm{LpA}_{2} \mathrm{I}_{2}$ of apoE3/3homozygotes $(P<0.05$ [pulse], $P<0.001$ [chase], Student's $t$ test; Table III).

Pulse-incubations of plasmas from apoE4/4-individuals led to the appearance of radioactivity in pre $\beta_{1}$-LpA-I $(8 \pm 2 \%), \alpha$ $\mathrm{LpA}_{3} \mathrm{I}_{3}(35 \pm 9 \%), \alpha-\mathrm{LpA}_{2}(13 \pm 3 \%)$, and LDL $(42 \pm 11 \%)$. The fraction with the electrophoretic properties of $\gamma$-LpE contained only close to background radioactivity $(2 \pm 1 \%$; Table III) as it becomes also obvious by the insignificant decrease of radioactivity in this particle during chase. After both pulse and chase, $\alpha$-LpA-I $\mathrm{I}_{2}$ of apoE4/4-homozygotes contained $65 \%$ less radioactivity than $\alpha$-LpA- $\mathrm{I}_{2}$ of apoE3/3-homozygotes ( $P$ $<0.001$, Student's $t$ test). Chase incubations in the absence of cells led to little changes of radioactivity in $\gamma-\operatorname{LpE}(1.5 \%), \alpha$ LpA-I $\mathrm{I}_{3}(31 \pm 8 \%), \alpha$-LpA-I $\mathrm{I}_{2}(15 \pm 3 \%)$, and significant decrease in pre $\beta_{1}$-LpA-I $(2 \pm 1 \%)$ and increase in LDL $(50 \pm 13 \%)$.

Effects of lipids, lipoproteins, apolipoproteins, and HDLsubfractions on $\left[{ }^{3} \mathrm{H}\right]$ cholesterol efflux from fibroblasts into total plasma and HDL-subfractions. Since some lipid values varied between individuals depending on their apoE-phenotype (see Tables I and II), we tested in a regression analysis, whether plasma concentrations of lipids, lipoproteins, and apolipoproteins influence $\left[{ }^{3} \mathrm{H}\right]$ cholesterol efflux into plasma and HDLsubfractions ( Table IV). Uptake of cell-derived $\left[{ }^{3} \mathrm{H}\right]$ cholesterol by $\gamma$-LpE, which may serve as an indirect estimation of $\gamma$ $\mathrm{LpE}$-serum concentration, was the only factor which correlated significantly with $\left[{ }^{3} \mathrm{H}\right]$ cholesterol-efflux into total plasma $(P$ $<0.01$, Pearson test). Interestingly, the positive correlations of $\left[{ }^{3} \mathrm{H}\right]$ cholesterol efflux with both HDL-cholesterol and apoA-I, as well as its negative correlation with total apoE levels remained stable also after differentiation by apoE-phenotype. By contrast, the negative correlations of cholesterol, triglycerides, LDL-cholesterol, and HDL-apoE with $\left[{ }^{3} \mathrm{H}\right]$ chlolesterol efflux in the entire population changed to positive correlations if only data of apoE3/3-samples were considered.

We also analyzed by regression analysis whether concentrations of lipids, lipoproteins, and apolipoproteins correlate with the uptake of cell-derived $\left[{ }^{3} \mathrm{H}\right]$ cholesterol by certain HDL-subfractions. $\left[{ }^{3} \mathrm{H}\right]$ cholesterol-efflux into $\gamma$-LpE and pre $\beta_{1}-\mathrm{LpA}-\mathrm{I}$ correlated positively with levels of HDL-cholesterol $(P<0.01$ and $P<0.001$, respectively) and apoA-I (both $P<0.05$ ) (Table IV).

\section{Discussion}

The ability of HDL to take up cellular cholesterol into the plasma compartment has been mainly attributed to apoA-I, the predominant protein component of HDL. However, both apoAI-deficient plasma (30) and apoA-I-depleted plasma (31) maintain $\sim 50 \%$ of a normal plasma's activity to remove cholesterol from cells. These observations suggest that apoA-I-free lipoproteins also contribute to reverse cholesterol transport. We have recently identified a plasma lipoprotein, $\gamma$ - $\mathrm{LEE}$, in which apoE is the only protein component and which, like pre $\beta_{1}-\mathrm{LpA}-$ I, serves as an initial acceptor of cell-derived cholesterol into the plasma compartment (19-21). In this study, we found that $\gamma$-LpE is immunodetectable only in plasmas of individuals who express at least one apoE3-allele but not in plasmas of individuals with apoE2/2, apoE4/4, and apoE2/4 (Fig. 1). During a 


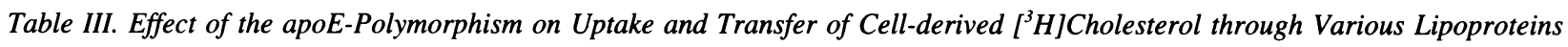

\begin{tabular}{|c|c|c|c|c|c|c|}
\hline & \multicolumn{2}{|c|}{ ApoE $3 / 3$} & \multicolumn{2}{|c|}{ ApoE $2 / 2$} & \multicolumn{2}{|c|}{ ApoE4/4 } \\
\hline & Pulse & Chase & Pulse & Chase & Pulse & Chase \\
\hline Total plasma & \multicolumn{2}{|c|}{$3642 \pm 414$} & \multicolumn{2}{|c|}{$2574 \pm 237$} & \multicolumn{2}{|c|}{$2562 \pm 222$} \\
\hline$\gamma-\mathrm{LpE}$ & $\begin{array}{l}537 \pm 156 \\
(19 \pm 5)\end{array}$ & $\begin{array}{r}104 \pm 13 \\
(4 \pm 1)\end{array}$ & $\begin{array}{c}76 \pm 27^{* * *} \\
\left(4 \pm 1^{* * *}\right)\end{array}$ & $\begin{array}{l}26 \pm 6^{* * *} \\
\left(1 \pm 1^{* * *}\right)\end{array}$ & $\begin{array}{c}40 \pm 33^{* * *} \\
\left(2 \pm 1^{* * *}\right)\end{array}$ & $\begin{array}{c}28 \pm 6^{* * *} \\
\left(2 \pm 1^{* * *}\right)\end{array}$ \\
\hline $\operatorname{Pre} \beta_{1}$-LpA-I & $\begin{array}{r}178 \pm 53 \\
(6 \pm 1)\end{array}$ & $\begin{array}{l}159 \pm 24 \\
(2 \pm 1)\end{array}$ & $\begin{array}{r}149 \pm 44 \\
(8 \pm 2)\end{array}$ & $\begin{array}{c}35 \pm 16 \\
(2 \pm 1)\end{array}$ & $\begin{array}{c}153 \pm 35 \\
(8 \pm 2)\end{array}$ & $\begin{array}{c}47 \pm 22 \\
(2 \pm 1)\end{array}$ \\
\hline$\alpha$-LpA-I ${ }_{3}$ & $\begin{array}{l}752 \pm 214 \\
(26 \pm 8)\end{array}$ & $\begin{array}{l}875 \pm 220 \\
(32 \pm 6)\end{array}$ & $\begin{array}{c}731 \pm 139 \\
(39 \pm 7 *)\end{array}$ & $\begin{array}{l}650 \pm 189 \\
(34 \pm 10)\end{array}$ & $\begin{array}{l}678 \pm 178 \\
(35 \pm 9)\end{array}$ & $\begin{array}{l}602 \pm 139 \\
(31 \pm 8)\end{array}$ \\
\hline$\alpha-\mathrm{LpA}-\mathrm{I}_{2}$ & $\begin{array}{l}713 \pm 220 \\
(25 \pm 8)\end{array}$ & $\begin{array}{l}810 \pm 159 \\
(30 \pm 5)\end{array}$ & $\begin{array}{l}394 \pm 118 * \\
(21 \pm 6)\end{array}$ & $\begin{array}{l}405 \pm 97 * * * \\
(21 \pm 5)\end{array}$ & $\begin{array}{c}240 \pm 52^{* * *} \\
(13 \pm 3 * * *)\end{array}$ & $\begin{array}{l}286 \pm 107^{* * *} \\
\left(15 \pm 3^{* * *}\right)\end{array}$ \\
\hline LDL & $\begin{array}{l}667 \pm 207 \\
(23 \pm 7)\end{array}$ & $\begin{array}{l}874 \pm 223 \\
(32 \pm 6)\end{array}$ & $\begin{array}{l}508 \pm 132 \\
(27 \pm 7)\end{array}$ & $\begin{array}{c}773 \pm 244 \\
(41 \pm 10)\end{array}$ & $\begin{array}{l}810 \pm 296 \\
\left(42 \pm 11^{* *}\right)\end{array}$ & $\begin{array}{l}964 \pm 245 \\
\left(50 \pm 13^{*}\right)\end{array}$ \\
\hline
\end{tabular}

Presented are mean values and standard deviations of either $\left[{ }^{3} \mathrm{H}\right]$ cholesterol either in total plasma or in the various lipoproteins as counts per minute. Data in brackets and italics give the percent radioactivity in a lipoprotein if the sum of radioactivity in all lipoproteins gives $100 \%$. Pulse incubations of $1 \mathrm{ml}$ plasma with radiolabeled fibroblasts were performed for $1 \mathrm{~min}$, chase incubations without cells for another one minute. Aliquots of $30 \mu \mathrm{l}$ plasma were then separated by 2D-PAGGE. The indicated lipoproteins were located in the gel by the use of anti-apoA-I and anti-apoE immunoblots, excised, and their lipids extracted. Radioactivity was counted by scintillation spectrometry. For further details see text. Two plasmas per apoEphenotype were analyzed. Each of the six plasmas was analysed three times in independent experiments. ${ }^{*} P<0.05 ;{ }^{* *} P<0.01 ;{ }^{* * *} P<0.001$ comparing by Student's $t$ test the mean values and standard deviations for $\left[{ }^{3} \mathrm{H}\right]$ cholesterol in the various lipoproteins of plasmas from apoE2/2- and apoE4/4-subjects to the radioactivity in the respective lipoproteins in plasmas from apoE3/3-individuals.

short incubation of plasma with $\left[{ }^{3} \mathrm{H}\right]$ cholesterol -labeled fibroblasts, $\gamma$-LpE of apoE3/3 individuals took up seven-fold and thirteen-fold more radioactivity than fractions with the mobility of $\gamma$-LpE in plasmas of apoE2/2- and apoE4/4-subjects, respectively (Table IV). Plasmas of apoE4/4-subjects rather appeared to be deficient in $\gamma$-LpE. The very low concentration or even absence of $\gamma$-LpE in plasmas of homozygotes for apoE2 and apoE4, respectively, is accompanied by a $30 \%$ decrease in efflux of cell-derived $\left[{ }^{3} \mathrm{H}\right]$ cholesterol during 1-min pulse as compared with plasmas of individuals homozygous for apoE3/3 (Table II). These data hence indicate an important role for $\gamma-\mathrm{LpE}$ in the uptake of cell-derived cholesterol into plasma. The possible importance of $\gamma-\mathrm{LpE}$ as a determinant of cholesterol efflux is also reflected by the positive correlation between $\left[{ }^{3} \mathrm{H}\right]-$ cholesterol-efflux into $\gamma$-LpE and $\left[{ }^{3} \mathrm{H}\right]$ cholesterol-efflux into total plasma (Table IV). A recent study found positive correlations of cholesterol efflux into plasma with levels of HDLcholesterol and apoA-I (32) which were also present in our study although insignificant possibly due to the low number of analyzed samples (Table IV). Differences in the degree of cholesterol efflux stimulation may thus be confounded by differences in the level of HDL-cholesterol (Tables I and II). Whether the apoE-polymorphism truly has an independent effect on cholesterol efflux must therefore be investigated in larger population-based studies.

The failure to immunodetect $\gamma$ - $\mathrm{LpE}$ in apoE3-free plasmas appears to reflect problems in the sensitivity rather than in the specificity of the antibodies. Firstly, the polyclonal anti-apoEantibodies used in these experiments detect apoE in native apoEcontaining lipoproteins varying in size and charge (Fig. 1) as

Table IV. Pearson Regression Analysis of Factors Possibly Affecting $\left[{ }^{3} \mathrm{H}\right]$ cholesterol Efflux from Fibroblasts into Plasma or HDL-subfractions

\begin{tabular}{|c|c|c|c|c|c|c|}
\hline & \multicolumn{6}{|c|}{$\left[{ }^{3} \mathrm{H}\right]$ cholesterol efflux into } \\
\hline & Total medium & $\gamma$-LpE & $\operatorname{Pre} \beta_{1}$-LpA-I & $\alpha-\mathrm{LpA}-\mathrm{I}_{3}$ & $\alpha-\mathrm{LpA}_{-} \mathrm{I}_{3}$ & LDL \\
\hline$\left[{ }^{3} \mathrm{H}\right]$ cholesterol-efflux & - & $0.89 * *$ & 0.53 & 0.16 & 0.50 & -0.01 \\
\hline Total cholesterol & -0.35 & 0.03 & 0.17 & 0.10 & -0.05 & 0.154 \\
\hline Triglycerides & -0.64 & -0.56 & -0.56 & 0.26 & -0.35 & -0.26 \\
\hline LDL-chol. & -0.54 & -0.22 & -0.06 & -0.02 & -0.27 & 0.12 \\
\hline HDL-chol. & 0.58 & $0.90 * *$ & $0.94 * * *$ & 0.14 & 0.67 & \pm 0 \\
\hline ApoA-I & 0.34 & $0.74 *$ & $0.81 *$ & -0.26 & 0.22 & -0.49 \\
\hline Plasma apoE & -0.59 & -0.43 & -0.40 & 0.16 & -0.28 & \pm 0 \\
\hline HDL-apoE & -0.62 & -0.47 & -0.41 & 0.16 & -0.29 & -0.09 \\
\hline
\end{tabular}

Correlations have been calculated on the basis of mean values of three experiments which have been performed with eight different plasma samples, namely from four subjects with apoE3/3, two subjects with apoE $2 / 2$, two subjects with apoE4/4 (see Table II). $* P<0.05$; $* * P<0.01 ; * * * P$ $<0.01$. 
well as in denatured and lipid-free apoE after IEF or SDSPAGE. This indicates that the antibodies recognize apoE rather than apoE-lipid complexes. Hence, epitope changes are unlikely to account for the failure to detect $\gamma$-LpE-species formed by apoE2 or apoE4. Second, also other polyclonal anti-apoEantisera detected $\gamma-\mathrm{LpE}$ in apoE3-containing plasmas but not in apoE3-free plasmas. Third, the failure to immunodetect $\gamma$ $\mathrm{LpE}$ in plasmas of apoE2/2- and apoE4/4-individuals correlates with the much lower ability of $\gamma$-LpE-like fractions in these plasmas to take up cell-derived $\left[{ }^{3} \mathrm{H}\right]$ cholesterol (Table III). In Western blots of plasma proteins separated by SDS-PAGE we determined the lower limit of detection for our visualization system with $0.15 \mathrm{ng}$ apoE. Since $30 \mu \mathrm{l}$ plasma have been separated by $2 \mathrm{D}-\mathrm{PAGGE}$, this would correspond to a $\gamma-\mathrm{LpE}$ plasma concentration of at least $5 \mathrm{ng} / \mathrm{ml}$. Based on this estimation, apoE3-containing plasmas transport $0.05-0.1 \%$ of HDL-apoE in $\gamma$-LpE (see Table I). Obviously, this borderline concentration is fallen below in individuals without apoE3. This may explain the discrepancy between immunologically undetectable $\gamma$-LpE but significant uptake of cell-derived $\left[{ }^{3} \mathrm{H}\right]$ cholesterol by this fraction in plasmas of apoE2/2-homozygotes. This discrepancy is analogous to the previous observation that pre $\beta_{3}-\mathrm{LpA}-$ $I$ is immunologically undetectable in many plasmas (even upon incubation of western blots with radiolabeled antibodies) although its cholesterol esterification activity can be assessed (references 21-23).

The structural features in apoE required to form $\gamma$ - $\mathrm{LpE}$ are as yet unknown. Previously, we found that sphingomyelin is the predominant lipid in $\gamma$-LpE (19). In this study, the importance of sphingomyelin in $\gamma$-LpE is demonstrated by our observation that $\gamma$-LpE in apoE3-containing plasmas is destroyed by incubation with sphingomyelinase but not through incubation with PC-PLC. Thus the formation of $\gamma-\mathrm{LpE}$ may depend on the ability of apoE to bind sphingomyelin. PC-PLC digests $\alpha$-LpE completely in plasmas of apoE3/3-individuals but incompletely in plasmas of homozygotes for apoE2 or apoE4 (Fig. 3). Thus apoE2 and apoE4 appear to protect phosphatidylcholine from enzymatic hydrolysis. In this context it is noteworthy that apoE2 and apoE4 exhibit a higher affinity for phosphatidylcholine than apoE3 (33). Increased affinity of apoE4 and apoE2 to some phospholipids or apolipoproteins may thus prevent the binding of sphingomyelin with these apoE isoforms and thereby hinder the formation of $\gamma$-LpE.

One possible prerequisite for a stable formation of $\gamma-\mathrm{LpE}$ may be the presence of apoE as a homodimer, since previously we found that $\gamma$-LpE contains apoE with an apparent molecular mass of $68 \mathrm{kD}$ (19). Lacking cysteine residues, apoE4 cannot dimerize and may therefore fail to form $\gamma$-LpE. Weisgraber and Shinto have recently demonstrated that apoE3-dimers are reduced in their binding affinity to the LDL-receptor (34). The presence of apoE3 as a homodimer in $\gamma$-LpE may thus be important in preventing the receptor-mediated uptake of this particle. Since apoE2 contains two cysteine residues and easily forms homodimers (35), this model cannot however explain the very low concentration of $\gamma$ - $\mathrm{LpE}$ in plasmas of homozygotes for apoE2.

As discussed before, the very low concentration of $\gamma-\mathrm{LpE}$ in apoE3-free plasmas may quantitatively affect cholesterol efflux. Moreover, the concentration of $\gamma$ - $\mathrm{LpE}$ also appears to affect the route by which cell-derived cholesterol is targeted from its initial acceptors to other lipoproteins. During both pulse and chase, significantly higher amounts of $\left[{ }^{3} \mathrm{H}\right]$ cholesterol accumu- lated in $\alpha$-LpA-I $\mathrm{I}_{2}$ of apoE3/3-carriers as compared to homozyogtes for apoE2 and apoE4 (Table III). This suggests that the uptake of cell-derived cholesterol by $\gamma$-LpE is followed by transfer to $\alpha$-LpA-I $\mathrm{I}_{2}$ whereas cholesterol taken up by pre $\beta_{1^{-}}$ LpA-I appears to be transferred preferentially to $\alpha-\mathrm{LpA}-\mathrm{I}_{3}$. In plasmas of apoE3-subjects, apoE in HDL is mostly colocalized with large-sized $\alpha$-LpA-I. Therefore, it may be that $\gamma$-LpE is converted into apoE-containing $\alpha-\mathrm{LpA}-\mathrm{I}_{2}$ and that this conversion/association process also transfers cholesterol. $\operatorname{Pre} \beta_{1}$-LpA$\mathrm{I}$, however, is first converted into $\alpha$-LpA-I $\mathrm{I}_{3}$ which is then converted into $\alpha$-LpA-I2 (36). This may explain the preferential appearance of cell-derived $\left[{ }^{3} \mathrm{H}\right]$ cholesterol in $\alpha$-LpA- $\mathrm{I}_{3}$ of plasmas from apoE2/2- and apoE4/4-subjects, which is characterized by low concentrations and activity of $\gamma-\mathrm{LpE}$.

The very low concentration or even absence of $\gamma-\mathrm{LpE}$ in plasmas from apoE4/4-homozygotes together with the impaired cholesterol efflux stimulating capacity of these plasmas raise the question as to whether these phenomena are causally linked to the increased cardiovascular risk of apoE4 individuals. At first sight, presence of $\gamma$-LpE in apoE3/4-heterozygotes and severely reduced concentrations of $\gamma-\mathrm{LpE}$ also in apoE2/2individuals would seem to rule out such a relationship. However, at least two arguments need further consideration: Firstly; our data do not exclude the possibility that heterozygosity for apoE3/2 and apoE3/4 affects the amount of $\gamma-\mathrm{LpE}$ in the extracellular space and hence reverse cholesterol transport. For example, the retarded elimination of apoE2-containing lipoproteins in apoE3/2 heterozygotes and enhanced clearance of apoE4-containing lipoproteins in apoE4/3 heterozygotes may influence the amount of $\gamma$-LpE formed by apoE3 $(7,8)$. It will be important in this respect to analyze how the apoEpolymorphism affects synthesis and secretion of apoE as well as the formation of $\gamma$-LpE by macrophages $(14,15,19)$. Secondly, since apoE2 binds poorly to apoE and apoB, E-receptors, macrophages in the arterial wall of apoE2/2-individuals take up less cholesterol via VLDL and their remnants (37). Consequently, despite impaired efflux of cellular cholesterol due to $\gamma$-LpEdeficiency, cholesterol homeostasis may be balanced in cells of apoE2-homozygotes, as it is the case in apoE3-homozygotes. By contrast, apoE4 does not interfere with cholesterol influx. Hence, decreased efflux of cholesterol may cause intracellular accumulation of cholesterol and increase arteriosclerotic risk in apoE4-subjects.

In conclusion, our study demonstrated that the apoE-polymorphism has a major effect on the formation of $\gamma$-LpE. Severely reduced concentrations or even absence of $\gamma-\mathrm{LpE}$ in plasmas without apoE3 may decrease cholesterol efflux from fibroblasts and appears to change the route by which cell-derived-cholesterol is delivered to LDL. Future studies are needed to demonstrate whether these qualitative and quantitative differences of reverse cholesterol transport exerted by the apoE-polymorphism have pathogenetic implications by accounting for at least some of the differences in cardiovascular risk associated with the apoE-polymorphism.

\section{Acknowledgments}

We gratefully acknowledge the excellent technical assistance of Anja Merschjan and Martina Plüster. We are also indebted to Dr. Paul Cullen for critically reading this manuscript.

The project was supported by a grant from Deutsche Forschungsgemeinschaft (Ec 116, 3-1) to A.v.Eckardstein. 


\section{References}

1. Mahley, R. W. 1988. Apolipoprotein E: cholesterol transport protein with expanding role in cell biology. Science (Wash. DC). 240:622-630.

2. Davignon, J., R. E. Gregg, and C. F. Sing. 1988. Apolipoprotein E polymorphism and atherosclerosis. Arteriosclerosis. 8:1-21.

3. Ordovas, J. M., and E. J. Schaefer. 1994. Apolipoprotein E polymorphisms and coronary heart disease risk. Cardiovascular Risk Factors. 4:103-107.

4. Mahley, R. W., and M. M. Hussain. 1991. Chylomicron and chylomicron remnant catabolism. Curr. Opin. Lipidol. 2:170-176.

5. Ishibashi, S., J. Herz, N. Maeda, J. L. Goldstein, and M. S. Brown. 1994. The two-receptor model of lipoprotein clearance: tests of the hypothesis in "knockout"'mice lacking the low density lipoprotein receptor, apolipoprotein E, or both proteins. Proc. Natl. Acad. Sci. USA. 91:4431-4435.

6. Weisgraber, K. H., T. L. Innerarity, and R. W. Mahley. 1982. Abnormal lipoprotein receptor-binding activity of the human $\mathrm{E}$ apolipoprotein due to cysteine-arginine interchange at a single site. J. Biol. Chem. 257:2518-2521.

7. Demant, T., D. Bedford, C. J. Packard, and J. Shepherd. 1991. Influence of apolipoprotein E polymorphism on apolipoprotein B-100 metabolism in normolipidemic subjects. J. Clin. Invest. 88:1490-1501.

8. Gregg, R. E., L. A. Zech, E. J. Schaefer, D. Stark, D. Wilson, D., H. B. Brewer, Jr. 1986. Abnormal in vivo metabolism of apolipoprotein E4 in humans. J. Clin. Invest. 78:815-821.

9. Eichner, J. E., L. H. Kuller, T. J. Orchard, G. A. Grandits, L. M. McCallum, R. E. Ferrell, and J. D. Neaton. 1993. Relation of apolipoprotein E phenotype to myocardial infarction and mortality from coronary artery disease. Am. J. Cardiol. 71:160-165.

10. Yamada, N., I. Inoue, M. Kawamura, M. Harada, Y. Watanabe, H. Shimano, T. Gotoda, M. Shimada, M. Kohzaki, T. Tsukada, M. Shiomini, Y. Watanabe, and Y. Yazaki. 1992. Apolipoprotein E prevents the progression of atherosclerosis in Watanabe heriTable hyperlipidemic rabbits. J. Clin. Invest. 89:706711.

11. Eisenberg, S. 1984. High density lipoprotein metabolism. J. Lipid Res. 25:1017-1058.

12. Tall, A. R. 1990. High density lipoproteins. Metabolism and relationship to atherogenesis. J. Clin. Invest. 86:379-384.

13. Johnson, W. J., F. H. Mahlberg, G. H., Rothblat, and M. C. Phillips. 1987, Cholesterol transport between cells and high density lipoproteins. Biochim. Biophys. Acta. 1085:273-298.

14. Basu, S. K., Y. Ho, M. S. Brown, D. W. Bilheimer, R. G. W. Anderson, and J. Goldstein. 1982. Biochemical and genetic studies of the apoprotein E secreted by mouse macrophages and human monocytes. J. Biol. Chem. 257:97889795.

15. Dory, L. 1989. Synthesis and secretion of apo E in thioglycolate-elicited mouse peritoneal macrophages: effect of cholesterol efflux. J. Lipid Res. 30:809816.

16. Koo, C., T. L. Innerarity, and R. W. Mahley. 1985. Obligatory role of cholesterol and apolipoprotein $\mathrm{E}$ in the formation of large cholesterol enriched and receptor-active high density lipoproteins. J. Biol. Chem. 260:11934-11943.

17. Gordon, V., T. L. Innerarity, and R. W. Mahley. 1983. Formation of cholesterol- and apoprotein $\mathrm{E}$ enriched high density lipoproteins in vitro. J. Biol. Chem. 258:6202-6212.

18. Funke, H., J. Boyles, K. H. Weisgraber, E. H. Ludwig, D. Y. Hui, and R. W. Mahley. 1984. Uptake of apolipoprotein E containing high density lipoproteins by hepatic parenchymal cells. Arteriosclerosis. 4:452-461.

19. Huang, Y., A. von Eckardstein, S. Wu, N. Maeda, and G. Assmann. 1994. A plasma lipoprotein containing only apolipoprotein $\mathrm{E}$ and with $\gamma$ mobility on electrophoresis releases cholesterol from cells. Proc. Natl. Acad. Sci. U.S.A. 91:1834-1838.
20. Castro, G. R. and C. J. Fielding. 1988. Early incorporation of cell-derived cholesterol into pre- $\beta$-migrating high density lipoprotein. Biochemistry. 27:2529.

21. Huang, Y., A. von Eckardstein, and G. Assmann. 1993. Cell-derived cholesterol cycles between different HDLs and LDL for its effective esterification in plasma. Arterioscler. Thromb. 13:445-458.

22. Asztalos, B. F., C. H. Sloop, L. Wong, and P. S. Roheim. 1993. Twodimensional electrophoresis of plasma lipoproteins: recognition of new apoA-I containing subpopulations. Biochim. Biophys. Acta. 1169:291-300.

23. Francone, O. L., A. Gurakar, and C. J. Fielding. 1989. Distribution and functions of lecithin:cholesterol acyltransferase and cholesterol ester transfer protein in plasma lipoproteins. J. Biol. Chem. 264:7066-7072.

24. Dallongeville, J., S. Lussier-Cacan, and J. Davignon. 1992. Modulation of plasma triglyceride levels by apo E phenotype. A meta analysis. J. Lipid Res. 33:447-454.

25. Friedewald, W. T., R. J. Lewis, and D. S. Fredrickson. 1972. Estimation of the concentration of low density lipoprotein cholesterol in plasma without the use of the preparative ultracentrifuge. Clin. Chem. 18:499-504.

26. Sandkamp, M., B. Tambyrajah, H. Schriewer, and G. Assmann. 1988. Simplified turbidimetric determination of apolipoproteins A-I, A-II and B using a microtitre method. J. Clin. Chem. Clin. Biochem. 26:685-689.

27. Hill, J. S., and P. H. Pritchard. 1990. Improved phenotyping of apolipoprotein E: Application to population frequency distribution. Clin. Chem. 36:18711874

28. Laemmli, U. K. 1970. Cleavage of structural proteins during the assembly of the head of bacteriophage T4. Nature (Lond.). 227:680-685.

29. Folch, J. M., M. Lees, and G. H. Sloane. 1957. A simple method for the isolation and purification of total lipids from animal tissues. J. Biol. Chem. 226:497-509

30. von Eckardstein, A., Y. Huang, S. Wu, H. Funke, G. Noseda, and G. Assmann. 1995. Uptake, transfer, and esterification of cell-derived cholesterol in plasma of patients with different forms of familial high density lipoprotein deficiency. Arterioscler. Thromb. Vasc. Biol. 15:691-703.

31. Kawano, M., T. Miida, C. J. Fielding, and P. E. Fielding. 1993. Quantitation of pre $\beta$-HDL-dependent and nonspecific component of the total efflux of cellular cholesterol and phospholipid. Biochemistry. 32:5025-5028.

32. de la Llera Moya, M., V. Atger, J. L. Paul, N. Fournier, N. Moatti, P. Giral, K. E. Friday, and G. M. Rothblat. 1994. A cell culture system for screening human serum for ability to promote cholesterol efflux. Relations between serum components and efflux, esterification, and transfer. Arterioscler. Thromb. 14:1056-1065.

33. Thuren, T., K. H. Weisgraber, P. Sisson, and M. Waite. 1992. Role of apolipoprotein $\mathrm{E}$ in hepatic lipase catalyzed hydrolysis of phospholipid in highdensity lipoproteins. Biochemistry. 31:2332-2338.

34. Weisgraber, K. H., and L. H. Shinto. 1991. Identification of the disulfidelinked homodimer of apolipoprotein E3 in plasma. J. Biol. Chem. 266:1202912034.

35. Weisgraber, K. H., and R. W. Mahley. 1978. Apoprotein (E-A-II) complex of human plasma lipoproteins I: Characterization of this mixed disulfide and its identification in a high density lipoprotein subfraction. J. Biol. Chem. 253:62816288.

36. Huang, Y., A. von Eckardstein, S. Wu, and G. Assmann. 1994. Generation of prebetal-high density lipoprotein (HDL) and its conversion into alpha-HDL: Evidence for disturbed HDL-conversion in Tangier disease. Atherosclerosis. 109:232 (abstr.)

37. Ishibashi, S., N. Yamada, H. Shimano, N. Mori, H. Mokuno, T. Gotoda, M. Kawakami, T. Murase, and F. Takaku. 1990. Apolipoprotein E and lipoprotein lipase secreted from human monocyte-derived macrophages modulate very low density lipoprotein uptake. J. Biol. Chem. 265:3040-3047. 